\title{
The Correlation of Knowledge Level About Exclusive Mother's Milk with Mother's Milk Deliverance To The Baby
}

Ina Kuswanti and Jenny Marcelina Faot

\section{Abstract}

Background: The giving of exclusive mother's milk was recommended for the baby until aged 6 months, because the mother's milk contained a full nutrients to grow and development for the baby. The successful in giving exclusive mother's milk was influenced by the mother's knowledge about the exclusive mother's milk. The data obtained also shownd that Danurejan 1 public healt was the lowest in exclusive breastfeeding gift that is $12,31 \%$. Results of interviews with mothers of babies $6-12$ months found mother's who did not breastfeed exclusive of 7 people.

Objective: To know the correlation of knowledge level of mother about exclusive mother's milk with the deliverance of exclusive mother's milk for the baby.

Method: This research used an analytic survey method with a cross sectional approach. The research population was 132 people, the research sample was 57 people taking with a purposive sampling method. The research instrument was a close questionnaire with Gutman Scale. The data analysis method used a frequency distribution and chi square correlation.

Result: The most mothers has a knowledge about exclusive mother's milk in a good categorized (50\%) and the most mothers gave the mother's milk exclusively (82,5\%). There were a significant correlation between mother's knowledge and exclusive mother's milk with the deliverance of exclusive mother's milk for the baby with $p$ count $=37,817$ with sig $0.000<0,05$.

Conclusion: There were a significant correlation between the mother's knowledge about exclusive mother's milk with the deliverance of exclusive mother's milk.

Key Words: Knowledge, The Deliverance of Exclusive Mother's Milk.

\section{Afiliasi Penulis}

STIKes Yogyakarta

J. Nitikan Baru No 69 Yogyakarta

Korespondensi kepada

I. Kuswanti

inna.nugroho@gmail.com 


\section{Hubungan Pengetahuan Ibu Tentang ASI Eksklusif dengan Pemberian ASI Eksklusif pada Bayi}

Ina Kuswanti dan Jenny Marcelina Faot

\section{Intisari}

Latar Belakang: Pemberian ASI eksklusif sangat dianjurkan pada bayi sampai berumur 6 bulan, karena ASI mengandug gizi yang lengkap untuk pertumbuhan dan perkembangan bayi. Keberhasilan pemberian ASI eksklusif dipengaruhi oleh pengetahuan ibu tentang tentang ASI eksklusif itu sendiri. Data yang diperoleh juga menyatakan bahwa Puskesmas Danurejan 1 merupakan Puskesmas yang menduduki peringkat terendah dalam pemberian ASI eksklusif yaitu sebesar (12,31\%). Hasil wawancara terhadap ibu yang mempunyai bayi 6-12 bulan didapatkan ibu yang tidak memberikan ASI secara eksklusif sebanyak 7 orang.

Tujuan: Untuk mengetahui hubungan tingkat pengetahuan ibu tentang ASI eksklusif dengan pemberian ASI eksklusif pada bayi.

Metode: Penelitian ini menggunakan metode Survey Analitik dengan pendekatan Cross Sectional. Populasi penelitian berjumlah 132 orang, sampel penelitian sebanyak 57 orang dengan metode Purposive Sampling. Instrumen penelitian berupa kuesioner tertutup dengan skala Gutman. Metode analisis data menggunakan distribusi frekuensi dan korelasi Chi Square.

Hasil: Sebagian besar ibu mempunyai pengetahuan tentang ASI eksklusif dalam kategori baik $(50,9 \%)$ dan kebanyakan ibu memberikan ASI secara eksklusif (82,5\%). Ada hubungan yang signifikan antara pengetahuan ibu tentang ASI eksklusif dengan pemberian ASI eksklusif pada bayi dengan $p$ hitung=37.817 dengan sig $0.000<0,05$.

Kesimpulan: Ada hubungan yang signifikan antara pengetahuan ibu tentang ASI eksklusif dengan pemberian ASI eksklusif

Kata Kunci: Pengetahuan, pemberian ASI eksklusif.

\section{Pendahuluan}

Pertumbuhan dan perkembangan bayi sebagian besar ditentukan oleh jumlah Air susu ibu (ASI) yang diperoleh termasuk energi dan zat gizi lainnya yang terkandung di dalam ASI tersebut. ASI tanpa bahan makanan lain dapat mencukupi kebutuhan pertumbuhan sampai usia bayi 6 bulan. ASI juga merupakan sebuah cairan untuk memenuhi kebutuhan gizi bayi dan melindungi dalam melawan kemungkinan serangan penyakit, pada saat yang sama ASI juga sangat kaya akan sari-sari makanan yang mempercepat pertumbuhan sel-sel otak dan perkembangan sistem saraf (Maryunani, 2015).

Dari 136,7 juta bayi lahir diseluruh dunia hanya $32,6 \%$ dari mereka yang disusui secara eksklusif dalam 6 bulan pertama, Sementara di negara berkembang hanya 39\% ibu-ibu yang memberikan ASI eksklusif. Di negara industri, bayi yang tidak diberi ASI eksklusif lebih besar meninggal dari pada bayi yang diberi ASI eksklusif (UNICEF, 2013). 
Menurut profil kesehatan Indonesia tahun 2013 persentase pemberian ASI eksklusif di Indonesia sebesar 54,3\%. Cakupan pemberian ASI eksklusif di provinsi D.I.Y sebesar 70,83\%, di Kota Yogyakarta pada tahun 2014 sebesar 54,9\%, tetapi cakupan ASI eksklusif ini belum sesuai Rencana Strategis Kementrian Kesehatan sebesar 80\% (Dinkes Kota Yogyakarta, 2014).

Menurut Profil Dinas Kesehatan Kota Yogakarta tahun 2014, di Puskesmas Danurejan 1 Yogyakarta Persentase bayi yang memperoleh ASI eksklusif sebesar 12,31\%, Puskesmas Danurejan 2 sebesar 54,84\%, Puskesmas Gondokusuman sebesar 67,74\%, Puskesmas Gondokusuman 2 sebesar $70,37 \%$, Puskesmas Gedongtengen sebesar 45,86\%, Puskesmas Jetis sebesar 78,95\%, Puskesmas Kotagede terdapat sebesar $45,77 \%$, Puskesmas Kotagede 2 sebesar 47,71\%, Puskesmas Mergangsan sebesar 54,61\%, Puskesmas Tegalrejo sebesar 94,29\%, Puskesmas Umbulharjo 1 sebesar 43,69\%, Puskesmas Umbulharjo 2 sebesar 69,93\% dan Puskesmas Wirobrajan sebesar 60,16\%. Dari data tersebut dapat disimpulkan bahwa cakupan ASI eksklusif di Puskesmas Danurejan 1 belum sesuai dengan Rencana Strategis Dinas Kesehatan Kota Yogyakarta sebesar $60 \%$ dan Rencana Strategis Kementrian Kesehatan sebesar $80 \%$.

Rendahnya pemberian air susu ibu (ASI) merupakan ancaman bagi tumbuh kembang anak. Seperti diketahui, bayi yang tidak diberi ASI, setidaknya hingga usia 6 bulan, lebih rentan mengalami kekurangan nutrisi. Terdapat Faktorfaktor yang mempengaruhi terhadap keberhasilan pemberian ASI eksklusif diantaranya yaitu pengetahuan, sikap ibu, dukungan suami dan aktivitas ibu (Setiowati, 2011).

Salah satu faktor yang mempengaruhi pemberian ASI eksklusif adalah tingkat pengetahuan. Tingkat pengetahuan yang relatif tinggi akan menyebabkan semakin tinggi pola pikir dan daya serap yang baik terhadap informasi tentang pemberian ASI eksklusif (Devita, 2013).

Berdasarkan hasil studi pendahuluan yang dilakukan pada tanggal 08 Maret 2016 di Puskesmas Danurejan 1, menunjukkan bahwa dari 10 orang ibu yang diwawancarai hasilnya 7 dari 10 orang ibu tidak memberikan ASI secara eksklusif dan 3 orang ibu memberikan ASI eksklusif.
Berdasarkan hasil studi pendahuluan tersebut, maka peneliti tertarik untuk melakukan penelitian tentang "Hubungan pengetahuan ibu tentang ASI eksklusif dengan pemberian ASI eksklusif pada bayi".

\section{Metode}

Penelitian ini merupakan jenis penelitian kuantitatif dengan menggunakan metode survey analitik dan dengan menggunakan pendekatan cross sectional. Penelitian ini dilakukan di Posyandu Pere Ayam wilayah kerja Puskesmas Danurejan 1 Yogyakarta pada tanggal 29-31 Agustus 2016.

Populasi dalam penelitian ini adalah ibu yang mempunyai bayi 6 sampai 12 bulan yang berjumlah 132 orang. Sampel dalam penelitian ini adalah ibuibu yang mempunyai bayi 6-12 bulan. Penentuan sampel dalam penelitian ini menggunakan metode Non Propabality Sampling, dengan metode purposive sampling. Dalam penelitian ini sampel yang diambil harus memenuhi criteria inklusi dan eksklusi.

Instrumen yang digunakan dalam penelitian ini adalah kuesioner. Responden dapat mengisi kuesioner tersebut dengan cara memberi tanda ( $V$ ) pada kotak yang menjadi pilihannya. Analisa data yang digunakan dalam penelitian ini adalah anlisa univariat. Analisa univariat dilakukan pada setiap variabel dari hasil penelitian untuk menghasilkan distribusi dan persentase dari tiap variabel. Analisis bivariat dilakukan dengan meggunakan uji chi square.

\section{Hasil dan Pembahasan}

\section{Pengetahuan ibu tentang ASI eksklusif}

Hasil penelitian menunjukkan bahwa pengetahuan ibu di Posyandu Pare Ayam yang memiliki pengetahuan baik sebanyak 29 orang $(50,9 \%)$, dan hanya terdapat 7 orang $(12,3 \%)$ memiliki pengetahuan kurang.

Menurut Siregar (2004), menjelaskan bahwa semakin cukup umur, tingkat kematangan dan kekuatan seseorang akan lebih matang dalam berfikir dan bekerja rata-rata responden dalam penelitian ini, sebagian besar berusia 20-30 tahun sebanyak 40 orang $(70,2 \%)$. Selain faktor usia, pekerjaan ibu juga berpengaruh dalam pemberian 
Tabel 1 | Distribusi karakteristik usia ibu di Posyandu Pare Ayam

\begin{tabular}{rcc} 
Usia & Frekuensi (n) & Persentase (\%) \\
\hline 20-30 tahun & 40 & 70,2 \\
31-40 tahun & 17 & 29,8 \\
\hline Total & 57 & 100
\end{tabular}

Sumber: Data primer, 2016

Tabel 2 | Distribusi karakteristik pendidikan ibu di Posyandu Pare Ayam

Pendidikan Frekuensi (n) Persentase (\%)

\begin{tabular}{rcc}
\hline SD & 7 & 12,2 \\
SMP & 8 & 14,0 \\
SMA/SMK & 38 & 66,7 \\
\hline Diploma/Sarjana & 4 & 7,1 \\
\hline Total & 57 & 100
\end{tabular}

Sumber: Data primer, 2016

ASI eksklusif, dari hasil penelitian rata-rata pekerjaan ibu di Posyandu Pare Ayam yang mempunyai pekerjaan sebagai ibu rumah tangga sebanyak 47 orang $(82,5 \%)$, dan yang bekerja sebanyak 10 orang $(17,5 \%)$. Dari hasil diatas didapatkan kelompok yang tidak bekerja rata-rata memiliki pengetahuan yang baik, hal ini dikarenakan karena ibu memiliki waktu dirumah dan aktivitas sosial yang tinggi sehingga arus informasi media elektronik mengenai ASI eksklusif mudah didapatkan. Hal ini menunjukan bahwa tingkat pengetahuan seseorang tidak dipengaruhi oleh pekerjaan namun juga dipengaruhi oleh tingginya informasi melalui media massa atau promosi kesehatan.

Menurut Notoatmodjo (2010) bahwa pendidikan mempengaruhi pengetahuan termasuk informasi kesehatan. Semakin tinggi pengetahuan seseorang semakin baik dalam upaya pencegahan penyakit begitupun sebaliknya. Pendidikan yang telah ditekuni sebagian besar ibu adalah sekolah menengah atas. Pendidikan mempengaruhi proses belajar, makin tinggi tingkat pendidikan seseorang makin mudah seseorang untuk menerima informasi. Dengan pendidikan tinggi seseorang akan cenderung untuk mendapatkan informasi, baik dari orang lain maupun dari media massa. Berdasarkan hasil penelitian didapatkan data responden lebih banyak berpendidikan SMA sebanyak 38 orang $(66,7 \%)$ dan paling sedikit
Tabel 3 | Distribusi karakteristik pekerjaan ibu di Posyandu Pare Ayam

Pekerjaan Frekuensi (n) Persentase (\%)

\begin{tabular}{rll}
\hline Tidak bekerja & 47 & 82,5 \\
Bekerja & 10 & 17,5 \\
\hline Total & 57 & 100
\end{tabular}

Sumber: Data primer, 2016

berpendidikan diploma/sarjana sebanyak 4 orang $(7,1 \%)$.

Pengetahuan ibu tentang ASI eksklsuif merupakan kemampuan ibu untuk mengetahui semua hal yang berkaitan dengan ASI. Tingkat pengetahua ibu tentang ASI eksklusif ikut menentukan mudah tidaknya ibu memahami dan menyerap informasi tentang ASI eksklusif. Semakin tinggi tingkat pengtahuan ibu maka makin tinggi pula kemampuan ibu untuk menyerap informasi tentang ASI eksklusif (Siregar, 2004).

Ibu yang memiliki pengetahuan baik dan cukup, bisa mereka peroleh dari pengalaman dan informasi yang diperoleh baik dari media massa maupun orang lain seperti penyuluhan, pendidikan kesehatan tentang manfaat ASI bagi bayi dari petugas kesehatan dan pemberitahuan dari kader. Semakin banyak informasi yang masuk semakin banyak pula pengetahuan yang didapat tentang kesehatan. Termasuk didalamnya pengetahuan ibu tentang pemberian ASI secara eksklusif. Hal tersebut sebagaimana dikemukanan oleh Ludvigson (2003) yang menyatakan bahwa pengetahuan ibu tentang menyusui berkaitan dengan tingkat pendidikan. Ibu yang mendapatkan informasi tentang menyusui dari seseorang, dokter, televisi majalah dan buku lebih banyak melanutkan menyusui dari pada ibu yang tidak mendapatkan informasi.

\section{Pemberian ASI eksklusif pada bayi}

Hasil penelitian yang telah diakukan menunjukkan bahwa ibu-ibu yang berada di Posyandu Pare Ayam sebagian besarmemberikan ASI eksklusif sebanyak 47 orang $(82,5 \%)$ dan hanya terdapat 10 orang $(17,5 \%)$ tidak memberikan ASI eksklusif pada bayinya.

Pemberian ASI membantu bayi memulai kehidupannya dengan baik. Kolestrum atau susu pertama mengandung antibodi yang kuat untuk mencegah infeksi dan membuat bayi lebih kuat. ASI 
Tabel 4 | Distribusi tingkat pengetahuan ibu di Posyandu Pare Ayam

\section{Pengetahuan Frekuensi (n) Persentase (\%)}

\begin{tabular}{rcc}
\hline Baik & 29 & 50,9 \\
Cukup & 21 & 36,8 \\
Kurang & 7 & 12,3 \\
\hline Total & 57 & 100
\end{tabular}

Sumber: Data primer, 2016

Tabel 5 | Distribusi pemberian ASI eksklusif pada bayi di Posyandu Pare Ayam

\begin{tabular}{rcc} 
Pemberian ASI & Frekuensi (n) & Persentase (\%) \\
\hline Diberikan & 47 & 82,5 \\
Tidak diberikan & 10 & 17,5 \\
\hline Total & 57 & 100
\end{tabular}

Sumber: Data primer, 2016

mengandung campuran yang tepat dari berbagai bahan makanan yang baik untuk bayi. ASI mudah dicerna oleh bayi. Pemberian ASI pada umumnya harus disarankan selama setidaknya satu tahun pertama kehidupan anak.

\section{Hubungan pengetahuan ibu tentang ASI}

eksklusif dengan pemberian ASI eksklusif

Hasil analisa bivariat menunjukkan nilai Chi Square sebesar 37,817 dengan signifikansi $p$ value $0,000<\alpha=0,05$. Hasil ini menunjukkan bahwa Ho ditolak, sehingga hipotesis penelitian ini menyatakan bahwa ada hubungan yang signifikan antara tingkat pengetahuan ibu dengan pemberian ASI eksklusif pada bayi.
Pengetahuan tentang pemberian ASI eksklusif sangat penting dimiliki oleh ibu. Ibu memiliki peran yang utama dalam meningkatkan dan mempertahankan kesehatan balita dan anak-anak dengan mendorong dirinya untuk lebih proaktif dalam menjaga kesehatan bayinya, dengan pemberian ASI secara eksklusif (Reskalia, 2013)

Menurut Reskalia (2013), pengetahuan ibu tentang ASI eksklusif dapat mempengaruhi ibu dalam menyusui. Semakin baik pengetahuan ibu tentang ASI eksklusif, maka seorang ibu akan memberikan ASI secara eksklusif pada anaknya. Rendahnya pemberian ASI merupakan ancaman bagi tumbuh kembang anak. Seperti diketahui, bayi yang tidak diberi ASI, setidaknya hingga usia 6 bulan, lebih rentan mengalami kekurangan nutrisi. Oleh karena itu diperlukan pengetahuan yang baik dalam pemberian ASI sebagai upaya dalam pencegahan penyakit namun sebaliknya jika pengetahuan ibu kurang akan berdampak pada kesehatan balitanya.

\section{Kesimpulan}

Penelitian yang bertujuan untuk mengetahui Hubungan Pengetahuan Ibu Tentang ASI eksklusif Dengan Pemberian ASI eksklusif pada bayi menghasilkan kesimpulan sebagai berikut:

1. Sebagian besar ibu di Posyandu Pare Ayam memiliki pengetahuan baik tentang ASI eksklusif.

Tabel 6 | Matriks pengetahuan ibu tentang ASI dan pemberian ASI eksklusif pada bayi di Posyandu Pare Ayam

\begin{tabular}{|c|c|c|c|c|c|c|}
\hline \multirow{3}{*}{ Pengetahuan } & \multicolumn{4}{|c|}{ Pemberian ASI } & \multirow{3}{*}{ Total } & \multirow{3}{*}{$\%$} \\
\hline & \multicolumn{2}{|c|}{ Diberikan } & \multicolumn{2}{|c|}{ Tidak diberikan } & & \\
\hline & $\mathrm{N}$ & $\%$ & $\mathrm{~N}$ & $\%$ & & \\
\hline Baik & 28 & 49,1 & 1 & 1 & 29 & 50,9 \\
\hline Cukup & 19 & 33,3 & 2 & 2 & 21 & 36,8 \\
\hline Kurang & - & 0 & 7 & 7 & 7 & 12,3 \\
\hline Total & 47 & 82,5 & 10 & 17,5 & & 100 \\
\hline
\end{tabular}

Tabel 7 | Uji korelasi Chi square antara pengetahuan ibu dengan pemberian ASI eksklusif pada bayi di Posyandu Pare Ayam

\begin{tabular}{rccc} 
Variabel & Chi square & Sig- $(\mathbf{p})$ & Hasil \\
\hline $\begin{array}{r}\text { Pengetahuan - } \\
\text { Pemberian ASI eksklusif }\end{array}$ & 37,817 & 0,000 & Ho ditolak
\end{tabular}


2. Sebagian besar ibu di Posyandu Pare Ayam sebagian besar memberikan ASI secara eksklusif pada bayi.

3. Ada hubungan yang signifikan antara pengetahuan ibu tentang ASI eksklusif dengan pemberian ASI eksklusif pada bayi, ditunjukan dengan hasil uji chi square dengan nilai signifikansi $p$ value $0,000<\alpha=0,05$.

\section{Bibliografi}

1. Siregar, A. (2004). Pemberian ASI eksklusif dan Faktor yang mempengaruhinya. Sumatra Utara: Universitas sumatra utara.

2. Devita, R. (2013). Faktor-Faktor Yang Berhubungan Dengan Pemberian ASI Eksklusif. Yogyakarta: Jurnal Kebidanan dan Keperawatan.

3. Dinas Kesehatan Kota Yogyakarta. (2014). Profil Kesehatan Kota Yogyakarta (Data Tahun 2014 ). Yogyakarta. Dinkes Kota Yogyakarta.

4. Ludvigson (2003). Breastfeeding intentions, patterns and determinats in infants visiting hospital in La paz, Bolovia 11 juni 2012 http://www.scielo/pdf/ijmorphol/v24n4/art 30.pdf

5. Maryunani, A. (2015). Inisiasi Menyusu Dini, ASI Eksklusif dan Manajemen Laktasi. Jakarta Timur: TIM.

6. Reskalia, I. (2013). Hubungan Antara Pengetahuan Dan Karakteristik Ibu Dengan Pemberian ASI Eksklusif Di BPM Endang Mergangsang Yogyakarta. Proposal STIKES Yogyakarta.

7. Notoatmodjo, S. (2010). IImu perilaku kesehatan, Jakarta : Rineka Cipta.

8. Setiowati, T. (2011). Hubungan Faktor-Faktor Ibu Dengan Pelaksana Pemberian Asi Eksklusif Pada Bayi 6-12 Bulan: Jurnal Kesehatan 2.

9. Unicef. 2013. Brestfeeding. http: // www.unicef. Org/ nutrition/ index 24824. html. Diakses 3 agustus 2016. 